\title{
Emergência e crescimento de plantas de cobertura em função da profundidade de semeadura ${ }^{1}$
}

\author{
Emergency and growth of cover crops in function of \\ the sowing depth
}

\author{
Leandro Pereira Pacheco ${ }^{2 *}$; Fábio Ribeiro Pires ${ }^{3}$; Fernando Pereira Monteiro ${ }^{4}$; \\ Sérgio de Oliveira Procópio ${ }^{5}$; Renato Lara de Assis ${ }^{6}$; Gilson Pereira Silva ${ }^{6}$; Alberto \\ Cargnelutti Filho $^{7}$; Marcos Lima do Carmo ${ }^{6}$; Fabiano André Petter ${ }^{8}$
}

\section{Resumo}

O objetivo do trabalho foi avaliar a emergência de cinco plantas de cobertura em diferentes profundidades de semeadura, visando à obtenção de informações que subsidiem sua utilização na consorciação e sobressemeadura de culturas anuais. $\mathrm{O}$ experimento foi conduzido em casa-de-vegetação, no delineamento experimental de blocos ao acaso, em esquema fatorial 5 x 7, composto pelas plantas de cobertura Pennisetum glaucum var. ADR 300, ADR 500 e BN2, Eleusine coracana e cober crop [híbrido de sorgo com capim-sudão (Sorghum bicolor x Sorghum sudanense)], e por sete profundidades de semeadura das plantas de cobertura $(0 \mathrm{~cm}$ sem presença de folhas de soja sobre as sementes, $0 \mathrm{com}$ presença de folhas de soja sobre as sementes, 1, 4, 8, 10 e $15 \mathrm{~cm}$ ). As sementes foram semeadas em vasos e as plantas cultivadas por 40 dias. Avaliaram-se o índice e o tempo de emergência, a altura de plantas, a fitomassa verde e seca da parte aérea, a área foliar, a fitomassa seca radicular e a densidade de comprimento radicular. Houve redução na emergência quando a semeadura foi realizada a zero $\mathrm{cm}$ com cobertura. Os milhetos e o híbrido S. bicolor x S. sudanense apresentaram restrições quanto ao uso em consórcio simultâneo. A semeadura realizada a $15 \mathrm{~cm}$ não deve ser utilizada.

Palavras-chave: Plantio direto, integração lavoura-pecuária, sobressemeadura, defasagem na emergência.

\begin{abstract}
The objective of this study was evaluated emergence of four cover crops at different seeding depths, in order to use them intercropped and oversown with annual crops. The experiment was installed in a greenhouse, and it was organized as a $5 \times 7$ factorial combination, with crop of five cover crops: Pennisetum glaucum var. ADR 300, ADR 500, and BN2, Eleusine coracana (finger millet), and a cober crop( hybrid sorghum with sudan-grass [Sorghum bicolor x Sorghum sudanese)]; seven cover crops seeding depths: $(0 \mathrm{~cm}$ without any mulch; $0 \mathrm{~cm}$ with a mulch of leaves over the seeds; $1 ; 4 ; 8 ; 10$; and 15 $\mathrm{cm}$ ). The cover crops were cropping in vases for 40 days. It was evaluated emergence index, emergence time, plant height, green biomass and dry biomass of the above-ground part, leaf area, root dry biomass
\end{abstract}

\footnotetext{
1 Parte da Dissertação de Mestrado do primeiro autor, apresentada à Universidade de Rio Verde - FESURV. Trabalho realizado na Universidade de Rio Verde, Rio Verde-GO.

2 Doutorando em Agronomia, UFG, Campus II, Goiânia, GO. E-mail: leandroppacheco@gmail.com (Bolsista CAPES).

3 Professor Adjunto do DCSBA, Faculdade de Agronomia, Centro Universitário Norte do ES/UFES. São Mateus, ES.

4 Graduando em Agronomia, Universidade de Rio Verde. Rio Verde, GO.

Pesquisador, Embrapa Tabuleiros Costeiros. Aracaju.

Professor Adjunto da Faculdade de Agronomia, Universidade de Rio Verde, GO.

Professor Adjunto do Dep. de Estatística, Universidade Federal do Rio Grande do Sul, Porto Alegre, RS.

8 Doutorando em Agronomia, UFG, Campus II, Goiânia, GO. (Bolsista CAPES)
} 
and root length density. There was reduction of emergence when cover crops was seeded at zero $\mathrm{cm}$ depth with a mulch of leaves, except for the E. coracana, that had a better performance in the oversown. Pearl millets and hybrid S. bicolor $\mathrm{x}$ S. sudanense show up some restrictions when used in simultaneous consortium. The $15 \mathrm{~cm}$ sowing depth must not be used.

Key words: No-tillage, integrated system, overcropping, delay in the emergence

\section{Introdução}

O sistema plantio direto (SPD) tem grande importância na sustentabilidade da produção agrícola. No entanto, para as condições de Cerrado, cuja área sob SPD ultrapassa vinte milhões de hectares (FEDERAÇÃO BRASILEIRA DE PLANTIO DIRETO NA PALHA - FEBRAPDP, 2007), tem apresentado dificuldade para atender dois requisitos básicos: rotação de culturas e formação/ manutenção de palhada (CERETTA et al., 2002; PIRES et al., 2007).

Como alternativa para viabilizar o SPD nessa região, tem-se difundido a integração lavourapecuária (ILP), que consiste no consórcio de plantas de cobertura com culturas anuais. Como uma modalidade de consórcio, o Sistema SantaFé objetiva a produção de palhada e/ou forragem para a entressafra - normalmente as espécies do gênero Brachiaria spp., em solos corrigidos, em áreas destinadas à produção de grãos das principais culturas anuais, com destaque para a cultura do milho (KLUTHCOUSKI; AIDAR, 2003). Por essa razão, as espécies utilizadas como opções de integração não devem interferir no cronograma de atividades e de exploração das culturas anuais no período de verão e, também, não competir com água (JEFFERIES, 1993) e nutrientes (PIRES et al., 2003). Além do mais, as espécies a serem utilizadas como planta de cobertura precisam apresentar alta relação $\mathrm{C} / \mathrm{N}$, como as gramíneas, contribuindo para a manutenção da palhada no solo (BOER et al., 2007).

A viabilidade técnica desse sistema tem sido demonstrada (PORTES et al., 2000), no entanto, as plantas de cobertura em consórcio simultâneo com culturas anuais necessitam ser suprimidas, principalmente em seu crescimento inicial, para que as últimas consigam sobressair-se na competição com as primeiras. Além do uso de subdoses de herbicidas seletivos à cultura anual (SILVA et al., 2005), a semeadura da planta de cobertura em maiores profundidades, mostra-se alternativa viável e capaz de favorecer o potencial competitivo da cultura anual consorciada (KLUTHCOUSKI; AIDAR, 2003). Em decorrência de ligeiro atraso na emergência, as plantas de cobertura ficam sombreadas e apresentam crescimento inicial mais lento, em razão do metabolismo $\mathrm{C}_{4}$ de fixação de $\mathrm{CO}_{2}$, característica que as tornam muito exigentes por luz (PORTES et al., 2000).

Essas evidências foram constatadas por Abreu (1993) que, trabalhando com Brachiaria brizantha em diferentes profundidades de semeadura, observou sensível redução na velocidade de emergência com o aumento da profundidade de deposição da semente. Apesar dessas informações, existem poucos estudos sobre o desempenho inicial de novas espécies que têm sido indicadas como plantas de cobertura quanto à profundidade de semeadura, que resulte em um atraso no tempo para germinação suficiente para evitar interferência na cultura anual, sem, contudo, prejudicar a planta de cobertura.

$\mathrm{O}$ milheto tem sido uma das principais plantas de cobertura utilizada para a produção de palhada no sistema plantio direto no Cerrado. Isso se dá devido ao crescimento rápido, com alta produção de fitomassa seca, mesmo em condições de baixa fertilidade (GEIGER; MANU, 1993) e umidade do solo no período após a colheita da cultura anual - safrinha (GONÇALVES et al., 2006; PIRES et al., 2007). O milheto e o capim-pé-de-galinha são gramíneas com potencialidades para serem introduzidas na integração lavoura-pecuária, com 
adequada produção de fitomassa e germinação na superfície do solo, o que possibilita serem cultivadas em sobressemeadura na soja (TRECENTI, 2005). A cultura do sorgo e seus híbridos também apresenta capacidade produzir grãos e palhada em condições de estresse hídrico para o sistema de plantio direto (LEHMANN et al., 1999). Os híbridos oriundos do seu cruzamento com sorgos africanos apresentam potencialidade de resistir com maior eficiência o estresse hídrico freqüente ocorrido durante a safrinha.

No caso da soja, mesmo adotando-se medidas para supressão da planta de cobertura, a cultura anual nem sempre apresenta desempenho satisfatório em consórcios simultâneos. Isso se dá devido à menor capacidade competitiva da soja em consórcio e à menor eficiência dos herbicidas utilizados em subdose para supressão de plantas de cobertura (SILVA et al., 2005). A altura de corte, por ocasião da colheita da soja, é outro fator que dificulta a consorciação.

Como alternativa promissora, tem-se difundido a sobressemeadura (a lanço) de plantas de cobertura, por ocasião da maturidade fisiológica da soja (início da desfolha: estádio $\mathrm{R}_{7}$ ) (TRECENTI, 2005), que proporciona elevada produção de palhada ou forragem e cobertura do solo no período de seca (outono-inverno) (LARA-CABEZAS, 2004). Dessa forma, tem-se maior flexibilidade no cronograma operacional da cultura, principalmente no processo de colheita de grãos, o que possibilitaria, com maior eficiência, a inclusão da soja na ILP. Todavia, o conhecimento sobre essapráticaéincipiente, havendo poucas informações que atestem sua eficiência, bem como apontem as plantas de cobertura mais indicadas para semeadura na superfície do solo.

O objetivo do trabalho foi avaliar a emergência e algumas características agronômicas de cinco plantas de cobertura em diferentes profundidades, visando ao seu emprego na consorciação e sobressemeadura de culturas anuais.

\section{Material e Métodos}

O experimento foi implantado em casa-devegetação da Universidade de Rio Verde, em Rio Verde, $\mathrm{GO}$ (Latitude $\mathrm{S}=17^{\circ} 48^{\prime}$, Longitude $\mathrm{W}=50^{\circ}$ 55', Altitude $760 \mathrm{~m}$ ). Utilizou-se solo classificado como Latossolo Vermelho Acriférrico para preenchimento dos vasos $\left(8 \mathrm{dm}^{3}\right)$. O solo, coletado na camada de 0-20 cm, apresentou $\mathrm{pH}\left(\mathrm{CaCl}_{2}\right) 4,09$; $\mathrm{Ca}, \mathrm{Mg}, \mathrm{Al}$, e H + Al de 0,006; 0,004; 0,005 e 0,29 mmol $_{c} \mathrm{dm}^{-3}$, respectivamente; K e P com 17 e 0,30 $\mathrm{mg} \mathrm{dm}{ }^{-3}$, respectivamente; CTC e SB com 0,320 e $0,032 \mathrm{mmol}_{\mathrm{c}} \mathrm{dm}^{-3}$, respectivamente; V (\%) 9,88; M.O. $12,79 \mathrm{~g} \mathrm{~kg}^{1}$; Areia, Silte e Argila 310, 150 e $540 \mathrm{~g} \mathrm{~kg}^{1}$, respectivamente.

O experimento foi implantado em blocos ao acaso com quatro repetições, em esquema fatorial 5 x 7, sendo cinco plantas de cobertura: Pennisetum glaucum (milheto) var. ADR 300, ADR 500 e BN2, Eleusine coracana (capim-pé-de-galinha) e cober crop - híbrido de sorgo com capim-sudão (Sorghum bicolor x Sorghum sudanense), e sete profundidades de semeadura das plantas de cobertura: semente depositada na superfície do solo (zero $\mathrm{cm}$ ), sem qualquer cobertura sobre as mesmas; semente depositada na superfície solo (zero $\mathrm{cm}$ ), coberta por folhas de soja e uma fina camada de solo sobre elas para evitar sua remoção pelo vento; e nas profundidades de semeadura de $1 ; 4 ; 8 ; 10$ e $15 \mathrm{~cm}$. Para calibração das profundidades de semeadura subsuperficiais foram pesados $8 \mathrm{~kg}$ de solo e acondicionados em cada vaso; depois, retirou-se todo o volume de solo acima da profundidade de semeadura requerida para cada tratamento, determinada com o auxílio de régua graduada; as sementes das plantas de cobertura foram então cuidadosa e uniformemente distribuídas e, em seguida, o solo retirado foi devolvido ao vaso, cobrindo as sementes.

Antes do preenchimento dos vasos, o solo foi peneirado em malha de $4 \mathrm{~mm}$, corrigido com calcário dolomítico filler, na dose de $2,5 \mathrm{Mg} \mathrm{ha}^{-1}$ 
(10 $\left.\mathrm{g} \mathrm{vaso}^{-1}\right), 30$ dias antes da semeadura, para alcançar a saturação por bases de $60 \%$; aplicaramse, posteriormente, $2,0 \mathrm{~g} \mathrm{vaso}^{-1}$ da fórmula 05-2515 . No dia $23 / 10 / 2005$ foram semeadas 20 sementes vaso $^{-1}$, sendo que, aos 14 dias após a semeadura (DAS), efetuou-se desbaste, deixando-se duas plantas por vaso para todas as espécies avaliadas, as quais foram cultivadas até 40 dias após a semeadura (DAS). Os vasos foram irrigados por microaspersão com turno de rega automático.

Determinou-se o índice de emergência (IE) das plantas de cobertura nas diferentes profundidades de semeadura, em que o total de plantas emergidas a $1 \mathrm{~cm}$ de profundidade foi considerado o padrão, $\mathrm{IE}=1$. Nos demais tratamentos, o IE foi calculado em relação ao número de plantas emergidas no tratamento padrão, em que: $\mathrm{IE}=$ número de plantas emergidas no tratamento $\mathrm{X} /$ número de plantas emergidas no tratamento padrão (profundidade de $1 \mathrm{~cm}$ ) estabelecido para cada planta de cobertura (PORTELLA; SATLER; FAGANELLO, 1997). O número de plantas emergidas foi contabilizado aos 14 DAS das plantas de cobertura, período a partir do qual o número de plantas emergidas se manteve constante. Determinou-se também o tempo de emergência (TE) das plantas em cada profundidade de semeadura (adaptado por MIRANDA; FERRAZ, 1999). Essa avaliação foi realizada medindo o tempo gasto, em dias, para emergência de $50 \%$ do número total de plantas por vaso. Considerou-se como emergida, a plântula que exibiu o primeiro coleóptilo exposto ou aberto.

Aos 20 e aos 40 DAS, foi determinada a altura de plantas, tomando-se como base para a medição o colo da planta até a extremidade do dossel. Aos 40 DAS foram avaliadas a área foliar (AF), as fitomassas verde (FV) e seca (FS) da parte aérea, fitomassa seca de raízes (FSR) e a densidade de comprimento radicular (DCR).

A AF foi obtida indiretamente por meio do produto das medidas de comprimento e largura de todas as folhas de cada planta, com auxílio de régua, multiplicado por 0,$73 ; 0,65 ; 0,68 ; 0,65$ e 0,73 , para BN2, ADR300, ADR500, híbrido S. bicolor x $S$. sudanense e capim-pé-de-galinha, respectivamente. Esses valores representam o coeficiente angular, usado como fator de ajuste da forma do limbo da folha, na estimativa da AF, obtido por meio da regressão do produto das dimensões da folha contra sua área real, obtida eletronicamente no programa computacional Quant Root v. 1.0, adaptado de Amaral (2002), após digitalização.

Para avaliação da FV e FS da parte aérea coletaram-se as duas plantas inteiras, seccionadas rente ao solo, sendo imediatamente pesadas. Após, foram secas em estufa, com circulação forçada de ar, por 72 horas a $65^{\circ} \mathrm{C}$, e pesadas, obtendo-se a FS.

A FSR foi obtida após a retirada, lavagem e secagem em estufa, com circulação forçada de ar, por 72 horas a $65^{\circ} \mathrm{C}$, de todo o sistema radicular contido no vaso, seguido de pesagem. Determinouse também a DCR dividindo-se o comprimento radicular total, obtido após digitalização das raízes e quantificação pelo programa Quant Root v. 1.0 (AMARAL, 2002), pelo volume total do vaso (8 $\left.\mathrm{dm}^{-3}\right)$.

Os dados foram submetidos à análise de variância e, quando pertinente, as médias dos tratamentos foram comparadas pelo teste Tukey, a $5 \%$ de significância.

\section{Resultados e Discussão}

Ao analisar o efeito da profundidade sobre o índice de emergência (IE), em geral, verificou-se significativa redução na semeadura a zero $\mathrm{cm}$ com cobertura vegetal e nas profundidades de $10 \mathrm{~cm} \mathrm{e}$ $15 \mathrm{~cm}$ para todas as plantas de cobertura (Tabela 1). Porém, na profundidade de $10 \mathrm{~cm}$, os milhetos apresentaram acima de $50 \%$ emergência do total de plantas emergidas na profundidade padrão (1 $\mathrm{cm}$ ), evidenciando, assim, o vigor dessas espécies para germinarem em profundidades maiores. Silva 
et al. (2002) e Obeid et al. (1994), trabalhando com aveia-branca (Avena sativa), não observaram diferenças quanto à emergência de plantas, nas diferentes profundidades de semeadura estudadas (3, 5 e $8 \mathrm{~cm})$. Para o capim-pé-de-galinha o efeito da profundidade de semeadura no IE foi ainda maior, ao ponto de impedir a emergência de plantas semeadas a 10 e $15 \mathrm{~cm}$ de profundidade. Isso reflete a maior dificuldade de estabelecimento dessa espécie quando semeada muito profunda, podendo afetá-la negativamente em consórcio na ILP, em razão ao reduzido tamanho das sementes dessa espécie, o que implica em limitado material de reserva para a emergência das plântulas.

Tabela 1. Índice de emergência (IE) e tempo de emergência (TE) aos 40 dias após a semeadura (DAS) em função da profundidade de deposição da semente.

\begin{tabular}{|c|c|c|c|c|c|c|c|}
\hline \multirow{2}{*}{$\begin{array}{l}\text { Planta de } \\
\text { cobertura }\end{array}$} & \multicolumn{7}{|c|}{ Profundidade $(\mathrm{cm})$} \\
\hline & 0 & $0 \mathrm{cob}$ & 1 & 4 & 8 & 10 & 15 \\
\hline & \multicolumn{7}{|c|}{ IE* } \\
\hline $\mathrm{BN} 2$ & $0,83 \mathrm{Aab}$ & $0,42 \mathrm{Abc}$ & $1,00 \mathrm{Aa}$ & $0,95 \mathrm{Aa}$ & $0,89 \mathrm{Aa}$ & 0,67 Aabc & $0,28 \mathrm{Ac}$ \\
\hline Hib. de sorgo & 0,91 Aab & $0,49 \mathrm{Abc}$ & 1,00 Aa & $1,00 \mathrm{Aa}$ & $0,75 \mathrm{Aab}$ & $0,30 \mathrm{Ac}$ & $0,16 \mathrm{Ac}$ \\
\hline Pé-de-galinha & 0,77 Aab & $0,68 \mathrm{Ab}$ & $1,00 \mathrm{Aa}$ & $0,52 \mathrm{Bb}$ & $0,16 \mathrm{Bc}$ & $* * *$ & $* * *$ \\
\hline ADR300 & $0,79 \mathrm{Ab}$ & $0,31 \mathrm{Ac}$ & $1,00 \mathrm{Aa}$ & $0,94 \mathrm{Aa}$ & $0,83 \mathrm{Aab}$ & $0,57 \mathrm{Ab}$ & $0,15 \mathrm{Ac}$ \\
\hline ADR500 & $1,00 \mathrm{Aa}$ & $0,29 \mathrm{Ac}$ & $1,00 \mathrm{Aa}$ & $1,00 \mathrm{Aa}$ & $1,00 \mathrm{Aa}$ & $0,56 \mathrm{Ab}$ & $0,23 \mathrm{Ac}$ \\
\hline \multirow[t]{2}{*}{ C.V (\%) } & \multicolumn{7}{|c|}{32,32} \\
\hline & \multicolumn{7}{|c|}{ TE (dias)** } \\
\hline $\mathrm{BN} 2$ & $6,25 \mathrm{Aa}$ & $6,25 \mathrm{Aa}$ & $6,00 \mathrm{Aa}$ & $6,00 \mathrm{Ba}$ & $6,50 \mathrm{Ba}$ & $7,75 \mathrm{Ab}$ & $9,25 \mathrm{Ab}$ \\
\hline Hib. de sorgo & 7,50 Aab & $6,00 \mathrm{Aa}$ & $6,00 \mathrm{Aa}$ & $6,00 \mathrm{Ba}$ & 7,50 Bab & $9,00 \mathrm{Abc}$ & $10,75 \mathrm{Ac}$ \\
\hline Pé-de-galinha & $6,75 \mathrm{Aa}$ & 7,75 Aa & 7,75 Aa & $9,00 \mathrm{Aa}$ & $11,50 \mathrm{Ab}$ & $* * *$ & $* * *$ \\
\hline ADR300 & $6,00 \mathrm{Aa}$ & $6,00 \mathrm{Aa}$ & $6,00 \mathrm{Aa}$ & $6,00 \mathrm{Ba}$ & 7,50 Bab & $8,75 \mathrm{Abc}$ & $10,25 \mathrm{Ac}$ \\
\hline ADR500 & $8,00 \mathrm{Aabc}$ & $6,00 \mathrm{Aa}$ & $6,00 \mathrm{Aa}$ & $6,00 \mathrm{Ba}$ & $6,75 \mathrm{Bab}$ & $9,00 \mathrm{Abc}$ & $9,50 \mathrm{Ac}$ \\
\hline C.V $(\%)$ & \multicolumn{7}{|c|}{15,27} \\
\hline
\end{tabular}

Médias seguidas de mesma letra maiúscula na coluna e minúscula na linha não diferem entre si, pelo teste de Tukey, a $5 \%$.

* O total de plantas emergidas a $1 \mathrm{~cm}$ de profundidade foi considerado $=1$. Os demais valores foram obtidos em relação a esta profundidade, de forma proporcional.

** Índice obtido pelo tempo necessário para a emergência de 50\% do total de plantas emergidas até 14 dias após a semeadura.

*** Tratamentos em que não se observaram emergência de plantas

$\mathrm{Na}$ presença de cobertura vegetal sobre as sementes depositadas na superfície, o capim-pé-degalinhademonstroubom desempenhona emergência, com possibilidades de uso em sobressemeadura na cultura da soja, assim como o milheto BN2 e o híbrido $S$. bicolor $\mathrm{x}$ S. sudanense. Em razão ao menor tamanho das sementes dessas espécies em relação às demais, há maior contato destas com o solo, o que conferiu maior germinação. Por outro lado, para as demais espécies, as folhas que cobriram as sementes constituíram-se em barreiras ao processo germinativo, resultante, possivelmente, de menor umidade nesse tratamento devido à interceptação e retenção de água promovida pelas folhas.

Outra possibilidade é a ocorrência de alelopatia, decorrente da decomposição do material vegetal utilizado na cobertura das sementes. Redução da atividade mitótica em células radiculares de plantas de milho foram observados com extrato de plantas de leucena (Leucaena leucocephala) (PIRES et al., 2001). O impedimento observado, todavia, discorda das observações de Altmann (2001), que aponta a 
cobertura exercida pelas folhas da cultura anual, sobrepostas às sementes das plantas de cobertura, como requisito essencial à emergência destas últimas, pois aumentam o contato com o solo e, conseqüentemente, auxiliam na proteção contra a desidratação das sementes em caso de estresse hídrico. Apesar das limitações apresentadas, os resultados com a semente coberta apontam o capim pé-de-galinha como uma espécie potencialmente indicada para prática da sobressemeadura, concordando como os resultados obtidos por Trecenti (2005), em que o milheto cv BN2 e o Eleusine coracana foram às espécies com maior emergência em sobressemeadura na soja.

No tempo de emergência (TE), houve atraso na emergência apenas a partir de $10 \mathrm{~cm}$ de profundidade, exceto para o capim-pé-de-galinha. Em média, até essa profundidade, as plantas levaram entre seis a sete dias para alcançar 50\% de emergência (Tabela 1). O retardamento na emergência de plantas ocorrido a partir de $10 \mathrm{~cm}$ foi de um a dois dias. O capim pé-de-galinha, em razão ao tamanho das sementes, teve sua germinação retardada a partir de $4 \mathrm{~cm}$ de profundidade, chegando a quatro dias quando semeado a $8 \mathrm{~cm}$. No entanto, a redução no IE pode limitar seu uso em maior profundidade na ILP. Exceto para o capim-pé-de-galinha, até a profundidade de $10 \mathrm{~cm}$ há possibilidades de se obter estande ideal das plantas de cobertura e atraso na emergência, favorecendo, assim, o desenvolvimento das culturas anuais.

O aumento da profundidade de semeadura até 10 $\mathrm{cm}$, não afetou a $\mathrm{AP}$ de milheto BN2 e ADR500, aos 20 DAS, com exceção da profundidade zero sem cobertura (Tabela 2). No entanto, quando semeadas a $15 \mathrm{~cm}$, a redução na altura foi superior a $50 \%$. O híbrido $S$. bicolor x $S$. sudanense e o milheto ADR300 tiveram comportamentos similares. O capim pé-de-galinha apresentou redução na $\mathrm{AP}$ a partir de $8 \mathrm{~cm}$, corroborando a dificuldade de crescimento em profundidades maiores de semeadura. Considerando-se apenas a interceptação da radiação solar, um dos recursos de maior competitividade pelas plantas submetidas ao consórcio (KLUTHCOUSKI; AIDAR, 2003), a AP obtida nas duas avaliações, aos 20 e 40 DAS, indica que a velocidade de crescimento inicial das plantas de cobertura pode favorecê-las em consórcio simultâneo, podendo afetar o desenvolvimento da cultura anual. O híbrido $S$. bicolor x $S$. sudanense, semeado a $8 \mathrm{~cm}$ de profundidade, alcançou média superior a $45 \mathrm{~cm}$ de altura aos $40 \mathrm{DAS}$, valor esse superior ao de culturas anuais em mesmo período de desenvolvimento, como milho, feijão e soja, que podem atingir valores médios de $28 \mathrm{~cm}$ aos 30 DAS (MIRÓ; FERREIRA; ÁQUILA, 1998), $44 \mathrm{~cm}$ aos 60 DAS (OLIVEIRA; CARVALHO; MORAES, 2002) e $23 \mathrm{~cm}$ aos 30 DAS (PEIXOTO; SOUZA, 2002), respectivamente. Os milhetos também apresentaram AP elevado até $40 \mathrm{DAS}$, apontando ser uma espécie de alto risco se implantada em consórcio simultâneo com as culturas anuais. Isso se deve pela possibilidade dessas espécies em transpor, pelo crescimento em altura, o dossel das plantas concorrentes e interceptar quantidade significativa de luminosidade para seu crescimento, que, por outro lado, causaria prejuízos ao desenvolvimento das culturas anuais em consórcio.

O capim pé-de-galinha posicionou-se entre as plantas de cobertura com maior produção de $\mathrm{AF}$ até a profundidade de $4 \mathrm{~cm}$ (Tabela 3 ), que, aliado à reduzida $\mathrm{AP}$, configura-se como importante espécie a ser utilizada em consórcio com culturas anuais até esta profundidade. Porém, quando semeado à $8 \mathrm{~cm}$ de profundidade, a AF apresentou redução significativa, comprometendo seu desenvolvimento. Os milhetos, por sua vez, sobressaíram-se quanto à AF, o que concorda com o trabalho de Braz, Kliemann e Silveira (2005), os quais verificaram maior expansão foliar do milheto em relação às demais espécies testadas até aos 40 DAS. Contudo, essa espécie apresenta excessivo crescimento em AP, condição fundamental para ocorra maior interceptação luminosa, comparado à cultura anual em consórcio. 
Tabela 2. Altura de plantas (AP) das plantas de cobertura do solo aos 20 e 40 dias (DAS) em função da profundidade de deposição da semente.

\begin{tabular}{|c|c|c|c|c|c|c|c|}
\hline \multirow{2}{*}{$\begin{array}{l}\text { Planta de } \\
\text { cobertura }\end{array}$} & \multicolumn{7}{|c|}{ Profundidade $(\mathrm{cm})$} \\
\hline & 0 & $0 \mathrm{cob}$ & 1 & 4 & 8 & 10 & 15 \\
\hline & \multicolumn{7}{|c|}{$\mathrm{AP}-20 \mathrm{DAS}(\mathrm{cm})$} \\
\hline $\mathrm{BN} 2$ & $26,33 \mathrm{Aa}$ & $32,33 \mathrm{ABa}$ & $34,94 \mathrm{Aa}$ & $26,75 \mathrm{Ba}$ & $27,19 \mathrm{Aa}$ & $27,19 \mathrm{Aa}$ & $13,00 \mathrm{ABb}$ \\
\hline Hib. de sorgo & $24,63 \mathrm{Ab}$ & $37,44 \mathrm{Aa}$ & $36,63 \mathrm{Aa}$ & $36,94 \mathrm{Aa}$ & $24,44 \mathrm{Aab}$ & $21,00 \mathrm{Ab}$ & $18,13 \mathrm{Ab}$ \\
\hline Pé-de-galinha & $18,13 \mathrm{Aa}$ & $23,00 \mathrm{Ba}$ & $20,44 \mathrm{Ba}$ & $15,13 \mathrm{Cab}$ & $5,13 \mathrm{Bbc}$ & $0,00 \mathrm{Bc}$ & $0,00 \mathrm{Cc}$ \\
\hline ADR300 & $23,60 \mathrm{Aab}$ & $27,88 \mathrm{ABab}$ & $22,88 \mathrm{Bb}$ & $34,00 \mathrm{ABa}$ & $30,38 \mathrm{Aab}$ & $21,80 \mathrm{Ab}$ & $10,28 \mathrm{Abc}$ \\
\hline ADR500 & $17,00 \mathrm{Abc}$ & $30,44 \mathrm{ABa}$ & $29,00 \mathrm{Aab}$ & $31,38 \mathrm{ABa}$ & $27,88 \mathrm{Aa}$ & $26,83 \mathrm{Aab}$ & $7,43 \mathrm{BCc}$ \\
\hline \multirow[t]{2}{*}{ C.V (\%) } & \multicolumn{7}{|c|}{21,61} \\
\hline & \multicolumn{7}{|c|}{$\mathrm{AP}-40$ DAS $(\mathrm{cm})$} \\
\hline $\mathrm{BN} 2$ & $68,68 \mathrm{Aab}$ & $80,26 \mathrm{Aa}$ & 65,31 Aabc & $58,63 \mathrm{Abc}$ & $50,50 \mathrm{Acd}$ & $62,00 \mathrm{Abc}$ & $43,19 \mathrm{Ad}$ \\
\hline Hib. de sorgo & $48,00 \mathrm{BCab}$ & $52,75 \mathrm{Ba}$ & $47,81 \mathrm{Bab}$ & 49,38 ABab & $47,81 \mathrm{Aab}$ & $38,19 \mathrm{Cab}$ & $37,29 \mathrm{Abc}$ \\
\hline Pé-de-galinha & $46,50 \mathrm{Ca}$ & $48,38 \mathrm{Ba}$ & $48,38 \mathrm{Ba}$ & $38,25 \mathrm{Ba}$ & $13,30 \mathrm{Bb}$ & $0,00 \mathrm{Db}$ & $0,00 \mathrm{Cd}$ \\
\hline ADR300 & $61,76 \mathrm{ABa}$ & $55,50 \mathrm{Ba}$ & $53,44 \mathrm{ABa}$ & $54,94 \mathrm{Aa}$ & $55,81 \mathrm{Aa}$ & $47,00 \mathrm{BCa}$ & $27,98 \mathrm{Bb}$ \\
\hline ADR500 & $41,75 \mathrm{Cb}$ & $57,63 \mathrm{Ba}$ & $49,13 \mathrm{Bab}$ & $51,44 \mathrm{ABab}$ & $52,94 \mathrm{Aab}$ & $58,78 \mathrm{ABa}$ & $25,00 \mathrm{Bc}$ \\
\hline C.V $(\%)$ & \multicolumn{7}{|c|}{15,16} \\
\hline
\end{tabular}

Médias seguidas de mesma letra maiúscula na coluna e minúscula na linha não diferem entre si, pelo teste de Tukey, a 5\%.

Tabela 3. Área foliar (AF), fitomassa verde (FV) e seca (FS) da parte aérea das plantas de cobertura em função da profundidade de deposição da semente.

\begin{tabular}{|c|c|c|c|c|c|c|c|}
\hline \multirow{2}{*}{$\begin{array}{l}\text { Planta de } \\
\text { cobertura }\end{array}$} & \multicolumn{7}{|c|}{ Profundidade $(\mathrm{cm})$} \\
\hline & 0 & $0 \mathrm{cob}$ & 1 & 4 & 8 & 10 & 15 \\
\hline & \multicolumn{7}{|c|}{$\mathrm{AF}\left(\mathrm{cm}^{2}\right.$ planta $\left.^{-1}\right)$} \\
\hline $\mathrm{BN} 2$ & $403,75 \mathrm{Ba}$ & $335,72 \mathrm{Bb}$ & $388,33 \mathrm{Aa}$ & $312,16 \mathrm{Ab}$ & $267,26 \mathrm{Bb}$ & $302,47 \mathrm{Ab}$ & $299,45 \mathrm{Ab}$ \\
\hline Hib. de sorgo & $190,10 \mathrm{Ca}$ & $211,98 \mathrm{Ca}$ & $232,15 \mathrm{Ba}$ & $173,76 \mathrm{Ba}$ & $254,90 \mathrm{Ba}$ & $225,59 \mathrm{Ca}$ & $200,78 \mathrm{Ba}$ \\
\hline Pé-de-galinha & $465,54 \mathrm{Ba}$ & $518,58 \mathrm{Aa}$ & $398,51 \mathrm{Ab}$ & $362,38 \mathrm{Ab}$ & $182,00 \mathrm{Bc}$ & $0,00 \mathrm{Dd}$ & $0,00 \mathrm{Cd}$ \\
\hline ADR300 & $512,63 \mathrm{Aa}$ & $626,05 \mathrm{Aa}$ & $323,09 \mathrm{Ab}$ & $367,72 \mathrm{Ab}$ & $368,39 \mathrm{Ab}$ & $385,99 \mathrm{Ab}$ & $321,58 \mathrm{Bb}$ \\
\hline ADR500 & $581,11 \mathrm{Aa}$ & $577,09 \mathrm{Aa}$ & $392,90 \mathrm{Ab}$ & $270,68 \mathrm{Bc}$ & $370,39 \mathrm{Ab}$ & $350,03 \mathrm{Ab}$ & $264,80 \mathrm{Bc}$ \\
\hline \multirow[t]{2}{*}{ C.V (\%) } & \multicolumn{7}{|c|}{27,45} \\
\hline & \multicolumn{7}{|c|}{$\mathrm{FV}\left(\mathrm{g}_{\text {planta }}{ }^{-1}\right)$} \\
\hline $\mathrm{BN} 2$ & $18,63 \mathrm{Aab}$ & $19,36 \mathrm{Aa}$ & $17,24 \mathrm{Aab}$ & $10,38 \mathrm{ABb}$ & $9,93 \mathrm{Ab}$ & $9,12 \mathrm{Bab}$ & $8,90 \mathrm{Ba}$ \\
\hline Hib. de sorgo & $5,65 \mathrm{Ba}$ & $6,00 \mathrm{Ba}$ & $6,46 \mathrm{Ba}$ & $4,86 \mathrm{Ba}$ & 7,48 Aa & $6,33 \mathrm{Ca}$ & 7,64 BCa \\
\hline Pé-de-galinha & $17,48 \mathrm{Aa}$ & $18,84 \mathrm{Aa}$ & $17,08 \mathrm{Aab}$ & $14,79 \mathrm{Aab}$ & 8,34 Abc & $0,00 \mathrm{Cc}$ & $0,00 \mathrm{Cc}$ \\
\hline ADR300 & $23,45 \mathrm{Aab}$ & $25,41 \mathrm{Aa}$ & $15,46 \mathrm{Abc}$ & $15,43 \mathrm{Abc}$ & $14,73 \mathrm{Abc}$ & $15,85 \mathrm{Abc}$ & $13,20 \mathrm{Ac}$ \\
\hline ADR500 & $22,10 \mathrm{Aa}$ & $21,11 \mathrm{Aa}$ & $13,79 \mathrm{Abc}$ & $10,19 \mathrm{ABd}$ & 12,43 Acd & $12,67 \mathrm{Acd}$ & $9,35 \mathrm{Bd}$ \\
\hline \multirow[t]{2}{*}{ C.V $(\%)$} & \multicolumn{7}{|c|}{31,05} \\
\hline & \multicolumn{7}{|c|}{ FS $\left(\right.$ g planta $\left.^{-1}\right)$} \\
\hline $\mathrm{BN} 2$ & 3,05 Aba & $3,21 \mathrm{Aa}$ & $2,94 \mathrm{Aa}$ & $1,53 \mathrm{Ab}$ & $1,24 \mathrm{Ab}$ & $2,34 \mathrm{Aab}$ & $3,04 \mathrm{Aa}$ \\
\hline Hib. de sorgo & $0,76 \mathrm{Ca}$ & $1,15 \mathrm{Ba}$ & $1,16 \mathrm{Ba}$ & $1,65 \mathrm{Aa}$ & $1,73 \mathrm{Aa}$ & 0,79 Ba & $1,21 \mathrm{Ba}$ \\
\hline Pé-de-galinha & 2,03 Bab & $2,85 \mathrm{Aa}$ & 2,59 Aab & 1,83 Aab & $1,60 \mathrm{Ab}$ & $0,00 \mathrm{Cc}$ & $0,00 \mathrm{Cc}$ \\
\hline ADR300 & $3,18 \mathrm{Aab}$ & 3,73 Aa & $1,98 \mathrm{ABbc}$ & $1,96 \mathrm{Ac}$ & $2,34 \mathrm{Abc}$ & $2,11 \mathrm{Abc}$ & $1,81 \mathrm{Bc}$ \\
\hline ADR500 & 2,95 ABab & 3,51 Aa & $1,90 \mathrm{ABbc}$ & $1,46 \mathrm{Ac}$ & $2,01 \mathrm{Abc}$ & $2,50 \mathrm{Abc}$ & $1,11 \mathrm{Bc}$ \\
\hline C.V (\%) & \multicolumn{7}{|c|}{27,99} \\
\hline
\end{tabular}

Médias seguidas de mesma letra maiúscula na coluna e minúscula na linha não diferem entre si, pelo teste Tukey, a $5 \%$. 
Para o acúmulo de FV e FS, houve redução à medida em que se aumentou a profundidade de semeadura, exceto para o híbrido $S$. bicolor x $S$. sudanense (Tabela 3). Essa defasagem em relação a $1 \mathrm{~cm}$ de profundidade foi de aproximadamente $50 \%$ e $35 \%$ para FV e FS, respectivamente, quando a semeadura se deu a $8 \mathrm{~cm}$ de profundidade. Os milhetos exibiram pequena redução na produção de FS quando semeados em maior profundidade, e por esse parâmetro, parecem ser mais competitivos com a cultura anual. Este comportamento pode ser intensificado com o tempo de convivência entre as espécies em consórcio. Esses resultados concordam com os obtidos por Trecenti (2005) e Braz, Kliemann e Silveira (2005). Perin et al. (2004) também observou significativo acúmulo de fitomassa de milheto - acima de $7 \mathrm{Mg} \mathrm{ha}^{-1}$ de FS, tanto em cultivo solteiro quanto consorciado com Crotalaria juncea. Contudo, a semeadura em profundidades maiores para as culturas do milheto e híbrido $S$. bicolor x S. sudanense, mesmo produzindo satisfatória quantidade de FS, não é recomendada para o consórcio simultâneo com sementes adicionadas ao adubo no sulco de semeadura das culturas anuais, em razão ao seu excessivo crescimento principalmente em AP.

Os milhetos produziram maior fitomassa seca de raízes (FSR) e exibiram crescimento radicular mais agressivo, com as menores reduções com o aumento da profundidade de semeadura (Tabela 4). Os resultados obtidos para os milhetos concordam com os obtidos por Gonçalves et al. (2006), comparando o crescimento de plantas de cobertura em camadas de solo compactadas, que apontaram o milheto detentor dos maiores índices de FS da parte aérea e de raízes, dentre as plantas de cobertura avaliadas. Por outro lado, discordam de Piffer e Benez (2005), que ao avaliarem o desenvolvimento radicular de amaranto, milheto e capim-pé-degalinha em diferentes níveis de compactação do solo, observaram que a maior FSR foi obtida pelo capim-pé-de-galinha, em razão ao uso de milheto comum, com menor capacidade de crescimento, comparado aos milhetos melhorados ADR300 e ADR500, utilizados no presente trabalho e também nos estudos feitos por Gonçalves et al. (2006).

Tabela 4 - Fitomassa seca de raízes (FSR) e densidade de comprimento radicular (DCR) das plantas de cobertura em função da profundidade de deposição da semente.

\begin{tabular}{lccccccc}
\hline \multicolumn{1}{c}{$\begin{array}{c}\text { Planta de } \\
\text { cobertura }\end{array}$} & 0 & $0 \mathrm{cob}$ & 1 & 4 & 8 & 10 & 15 \\
\cline { 2 - 7 } & & \multicolumn{7}{c}{ FSR $\left(\mathrm{g} \mathrm{planta}{ }^{-1}\right)$} \\
\hline BN2 & $2,48 \mathrm{Bb}$ & $2,98 \mathrm{Aa}$ & $3,68 \mathrm{Aa}$ & $2,29 \mathrm{Ab}$ & $1,78 \mathrm{Bb}$ & $1,83 \mathrm{Ab}$ & $1,51 \mathrm{Ab}$ \\
Hib. de sorgo & $1,34 \mathrm{Cc}$ & $2,36 \mathrm{Ab}$ & $3,55 \mathrm{Aa}$ & $2,29 \mathrm{Ab}$ & $2,18 \mathrm{Bb}$ & $1,05 \mathrm{Bc}$ & $0,71 \mathrm{Ac}$ \\
Pé-de-galinha & $2,18 \mathrm{Bb}$ & $2,37 \mathrm{Ab}$ & $3,16 \mathrm{Aa}$ & $1,49 \mathrm{Bb}$ & $2,19 \mathrm{Bb}$ & $0,00 \mathrm{Bc}$ & $0,00 \mathrm{Bc}$ \\
ADR300 & $2,63 \mathrm{Ba}$ & $2,92 \mathrm{Aa}$ & $2,54 \mathrm{Ba}$ & $3,08 \mathrm{Aa}$ & $3,11 \mathrm{Aa}$ & $1,93 \mathrm{Aa}$ & $0,63 \mathrm{Ab}$ \\
ADR500 & $3,37 \mathrm{Aa}$ & $2,93 \mathrm{Aa}$ & $2,89 \mathrm{Ba}$ & $2,95 \mathrm{Aa}$ & $3,86 \mathrm{Aa}$ & $2,55 \mathrm{Aa}$ & $0,71 \mathrm{Ab}$ \\
\hline C.V (\%) & \multicolumn{7}{c}{31,17} \\
\hline \multicolumn{7}{c}{$\mathrm{DCR}\left(\mathrm{cm} \mathrm{cm}^{-3} \mathrm{de}\right.$ solo $)$} \\
\hline BN2 & $3,51 \mathrm{Bb}$ & $4,68 \mathrm{Aa}$ & $5,03 \mathrm{Aa}$ & $3,30 \mathrm{Ab}$ & $2,54 \mathrm{Bc}$ & $1,79 \mathrm{Bc}$ & $1,71 \mathrm{Ac}$ \\
Hib. de sorgo & $1,69 \mathrm{Cc}$ & $2,49 \mathrm{Bb}$ & $4,48 \mathrm{Aa}$ & $2,47 \mathrm{Bb}$ & $2,48 \mathrm{Bb}$ & $1,28 \mathrm{Cc}$ & $0,60 \mathrm{Bc}$ \\
Pé-de-galinha & $2,14 \mathrm{Ca}$ & $2,46 \mathrm{Ba}$ & $3,39 \mathrm{Aa}$ & $1,82 \mathrm{Ba}$ & $2,06 \mathrm{Ba}$ & $0,00 \mathrm{Cb}$ & $0,00 \mathrm{Bb}$ \\
ADR300 & $2,64 \mathrm{Ca}$ & $4,49 \mathrm{Aa}$ & $3,69 \mathrm{Aa}$ & $3,18 \mathrm{Aa}$ & $2,74 \mathrm{Ba}$ & $3,57 \mathrm{Aa}$ & $0,53 \mathrm{Bb}$ \\
ADR500 & $5,11 \mathrm{Aa}$ & $2,48 \mathrm{Bb}$ & $2,45 \mathrm{Bb}$ & $3,88 \mathrm{Aa}$ & $4,87 \mathrm{Aa}$ & $2,48 \mathrm{Bb}$ & $0,84 \mathrm{Bc}$ \\
\hline C.V (\%) & \multicolumn{7}{c}{41,27} \\
\hline
\end{tabular}

Médias seguidas de mesma letra maiúscula na coluna e minúscula na linha não diferem entre si, pelo teste Tukey, a 5 \%. 
Em relação à densidade de comprimento radicular (DCR) nota-se uma grande alternância nos resultados dentro de cada profundidade (Tabela 4). Essas divergências podem ser atribuídas ao comportamento inerente ao parâmetro raízes, cuja variabilidade é normalmente elevada. Apesar de nenhuma espécie ter se destacado, os milhetos BN2, ADR300 e ADR500 tiveram maior DCR em maior número de profundidades, concordando com os resultados obtidos por Gonçalves et al. (2006).

\section{Conclusões}

A semeadura na superfície do solo na ausência de folhas de soja sobre as sementes das plantas de cobertura e nas profundidades de 1 e $4 \mathrm{~cm}$ resulta em maior emergência para todas as espécies avaliadas. A presença de folhas de soja sobre as sementes das plantas de cobertura prejudica sua emergência. O crescimento excessivo em altura plantas até 40 dias após a semeadura apontam para restrições quanto ao uso dos milhetos e híbrido S. bicolor $\mathrm{x}$ S. sudanense em consórcio simultâneo. Para consórcio simultâneo, a profundidade de $10 \mathrm{~cm}$ é a mais indicada. A semeadura realizada a $15 \mathrm{~cm}$ não é indicada para semeadura das plantas de cobertura.

\section{Agradecimentos}

À Fundação Agrisus pelos recursos financeiros concedidos à pesquisa.

À CAPES pela concessão de Bolsa de Mestrado.

\section{Referências}

ABREU, J. G. Influência da profundidade de semeadura e da pressão de compactação no solo sobre a emergência de Brachiaria brizantha Stapf cv. Marandu. 1993. Dissertação. (Mestrado em Zootecnia) - Universidade Federal de Viçosa, Viçosa.

ALTMANN, N. Como iniciar em plantio direto (2 parte). In: LARA-CABEZAS, W. R.; FREITAS, P. L.
(Ed.) Plantio direto na integração lavoura-pecuária. Uberlândia: EDUFU, 2001. p. 217-233.

AMARAL, J. F. T. Eficiência de produção de raizes, absorção, translocação utilização de nutrientes em cultivares de café arábica. 2002. Tese. (Doutorado em Fitotecnia) - Universidade Federal de Viçosa, Viçosa.

BOER, C. A.; ASSIS, R. L.; SILVA, G. P.; BRAZ, A. J. P.; BARROSO, A. L. L.; CARGNELUTTI FILHO, A.; PIRES, F. R. Ciclagem de nutrientes por plantas de cobertura na entressafra em um solo de cerrado. Pesquisa Agropecuária Brasileira, Brasília, v. 42, n. 9, p. 12691276, 2007.

BRAZ, A. J. P.; KLIEMANN, H. J.; SILVEIRA, P. M. Produção de fitomassa de espécies de cobertura em latossolo vermelho distróférrico. Pesquisa Agropecuária Tropical, Goiânia, v. 35, n. 1, p. 55-64, 2005.

CERETTA, C. A.; BASSO, C. J.; HERBES, M. G.; POLletO, N.; SILVEIRA, M. J. Produção e decomposição de fitomassa de plantas invernais de cobertura de solo em milho sob diferentes manejos da adubação nitrogenada. Ciência Rural, Santa Maria, v. 32, n. 1, p. 49-54, 2002.

FEDERAÇÃO BRASILEIRA DE PLANTIO DIRETO NA PALHA - FEBRAPDP. Área de plantio direto no mundo. Ponta Grossa: FEBRAPDP, 2007.

GEIGER, S. C.; MANU, A. Soil surface characteristics and variability in the growth of millet in the plateau and valley region of Wastern Niger. Agriculture, Ecosystems \& Environment, Amsterdam, v. 45, n. 4, p. 203-211, 1993.

GONÇALVES, W. G.; JIMENEZ, R. L.; ARAÚJO FILHO, J. V.; ASSIS, R. L.; SILVA, G. P.; PIRES, F. R. Sistema radicular de plantas de cobertura sob compactação de solo. Engenharia Agrícola, Jaboticabal, v. 26, n. 1, p. 67-75, 2006.

JEFFERIES, R. A. Cultivar responses to water stress in potato: effects of shoot and roots. New Phytologist, Oxford, v. 123, n. 3, p. 491-498, 1993.

KLUTHCOUSKI, J.; AIDAR, H. Implantação, condução e resultados obtidos com o sistema Santa-fé. In: KLUTHCOUSKI, J.; AIDAR, H.; STONE, L. F. (Ed.) Integração lavoura-pecuária. Santo Antonio de Goiás: Embrapa Arroz e Feijão, 2003. p. 407-441.

LARA-CABEZAS, W. A. R. Sobressemeadura com sementes de milheto revestidas no Triângulo MineiroMG: estudo preliminar. Revista Plantio Direto, Passo Fundo, v. 79, n. 1, p. 16-18, 2004. 
LEHMANN, J.; FEILNER, T.; GEBAUER, G.; ZECH, W. Nitrogen uptake of sorghum (Sorghum bicolor L.) from tree mulch and mineral fertilizer under high leaching conditions estimated by nitrogen- 15 enrichment. Biology and Fertility of soils, Berlin, v. 30, n. 2, p. 90-95, 1999.

MIRANDA, P.R.M.; FERRAZ, I.D.K. Efeito da temperatura na germinação de sementes e morfologia de plântula de Maquira sclerophylla (Ducke) C.C. Berg. Revista Brasileira de Botânica, São Paulo, v. 22, n. 2, p. 303-307, 1999.

MIRÓ, C. P.; FERREIRA, A. G.; ÁQUILA, M. E. A. Alelopatia de frutos de erva-mate (Ilex paraguariensis) no desenvolvimento do milho. Pesquisa Agropecuária Brasileira, Brasília, v. 33, n. 8, p. 1261-1270, 1998.

OBEID, J. A.; GOMIDE, J. A.; CRUZ, M. E.; SILVA, S. P.; SILVA, S. P. Semeadura de gramíneas forrageiras tropicais: I. Profundidade de semeadura. Revista da Sociedade Brasileira de Zootecnia, Viçosa, v. 23, n. 6, p. 877-888, 1994.

OLIVEIRA, T. K.; CARVALHO, G. J.; MORAES, R. N.S. Plantas de cobertura e seus efeitos sobre o feijoeiro em plantio direto. Pesquisa Agropecuária Brasileira, Brasília, v. 37, n. 8, p. 1079-1087, 2002.

PEIXOTO, M. F.; SOUZA, I. F. Efeitos de doses de imazamox e densidades de sorgo (Sorghum bicolor (L.) Moench) em soja (Glycine max (L.) Merril) sob plantio direto. Ciência e Agrotecnologia, Lavras, v. 26, n. 2, p. 252-258, 2002.

PERIN, A.; SANTOS, R. H. S.; URQUIAGA, S.; GUERRA, J. G. M.; CECON, P. R. Produção de fitomassa, acúmulo de nutrientes e fixação biológica de nitrogênio por adubos verdes em cultivo isolado e consorciado. Pesquisa Agropecuária Brasileira, Brasília, v. 39, n. 1, p. 35-40, 2004.

PIFFER, C. R.; BENEZ, S. H. Desenvolvimento do sistema radicular de amaranto, milheto e pé-de-galinha em diferentes níveis de compactação. Energia na Agricultura, Botucatu, v. 20, n. 1, p. 50-52, 2005.
PIRES, F. R.; SOUZA, C. M.; QUEIROZ, D. M.; MIRANDA, G. V.; GALVÃO, J. C. C. Alteração de atributos químicos do solo e estado nutricional e características agronômicas de plantas de milho, considerando as modalidades de calagem em plantio direto. Revista Brasileira de Ciência do Solo, Campinas, v. 27, n. 1, p. 121-131, 2003.

PIRES, F. R.; ASSIS, R. L.; SILVA, G. P.; BRAZ, A. J. B. P.; SANTOS, S. C. G.; VIEIRA NETO, S. A.; SOUSA, J. P. G. Desempenho agronômico de três variedades de milheto em função da época de manejo em pré-safra. Bioscience Journal, Uberlândia, v. 23, n. 1, p. 41-49, 2007.

PIRES, N. M.; SOUZA, I. R. P.; PRATES, H. T.; FARIA, T. C. L.; PEREIRA FILHO, I. A.; MAGALHÃES, P. C. Efeito do extrato aquoso de leucena sobre o desenvolvimento, índice mitótico e atividade da peroxidase em plântulas de milho. Revista Brasileira de Fisiologia Vegetal, Brasília, v. 13, n. 1, p. 55-65, 2001.

PORTELlA, J. A.; SATLER, A.; FAGANELlO, A. Índice de emergência de plântulas de soja e de milho em semeadura direta no sul do Brasil. Engenharia Agrícola, Sorocaba, v. 17, n. 2, p. 71-78, 1997.

PORTES, T. A.; CARVALHO, S. I. C.; OLIVEIRA, I. P.; KLUTHCOUSKI, J. Análise do crescimento de uma cultivar de braquiária em cultivo solteiro e consorciado com cereais. Pesquisa Agropecuária Brasileira, v. 35, n. 7, p. 1349-1358, 2000.

SILVA, A. C.; FERREIRA, L. R.; SILVA, A. A.; BELO, A. F.; SEDIYAMA, C. S. Caracteres morfológicos de soja e braquiária consorciadas. Ciência Rural, Santa Maria, v. 35, n. 2, p. 277-283, 2005.

SILVA, T. V.; HOMECHINI, M.; ENDO, R. M.; FONSECA, I. C. B. Efeito do tratamento de semente e da profundidade de semeadura no desenvolvimento de plantas de aveia-branca (Avena sativa L.) e a microflora da rizosfera e do rizoplano. Revista Brasileira de Sementes, Brasília, v. 24, n. 1, p. 237-243, 2002.

TRECENTI, R. Avaliação de características agronômicas de espécies de cobertura vegetal do solo em cultivos de entressafra e sobressemeadura, na região central do cerrado. 2005. Dissertação. (Mestrado em Fitotecnia) Universidade de Brasília, Brasília. 